\title{
The ETS in China and Europe: dynamics, policy options and global sustainability perspectives
}

\author{
Paul J. J. Welfens ${ }^{1,2,3} \cdot$ Nan Yu ${ }^{1,2}$. \\ David Hanrahan ${ }^{1,2} \cdot$ Yong Geng ${ }^{4}$
}

Published online: 24 July 2017

(C) The Author(s) 2017. This article is an open access publication

\begin{abstract}
The Emission Trading Schemes of China and Europe show that China's envisaged national ETS could bring a major contribution in the international approach against global warming; new perspectives on the use of composite sustainability indicators are also highlighted. China's regional pilot schemes will converge to a (more) uniform price of emission allowances. As China is a major economic and political actor in the world economy, China's progress with ETS is important. At the same time, China's progress in the field of green international competitiveness standing for a positive revealed comparative advantage in environmentally friendly goods - in the period 2000-2015 is considerable and the improved positioning of China in the EIIW-vita sustainability indicator shows considerable technological dynamics in Asia. The European ETS is working, but it suffers from the rather low price of emission allowances. The long-term time horizon of 2050 in the EU climate policy is rather ambitious and it is unclear whether or not a consistent G20 approach can be achieved - with the EU, China, Japan and the US cooperating amongst each other. There is a lack of a specialized climate stabilization institution in the world economy, the traditional anchoring of climate policy in the UN weakens the practical pressure for efficient cooperation since the UN is very heterogeneous in terms of per capita income and GHG emissions per unit of GDP; G20 might be an institution that is suitable for effective policy cooperation. More initiatives in the field of recycling could be useful.
\end{abstract}

Paul J. J. Welfens

welfens@uni-wuppertal.de; welfens@eiiw.uni-wuppertal.de; http://www.eiiw.eu;

http://www.econ-international.net

1 European Institute for International Economic Relations, University of Wuppertal (EIIW), Rainer-Gruenter-Str. 21, D-42119 Wuppertal, Germany

2 Schumpeter School of Business and Economics, University of Wuppertal, Gaußstr. 20, D-42119 Wuppertal, Germany

3 AICGS/Johns Hopkins University, Washington DC, USA

4 Shanghai Jiao Tong University, Shanghai, China 
Keywords Emission trading systems $\cdot$ Carbon trading $\cdot$ Europe $\cdot$ China $\cdot$ EU $\cdot$ Greenhouse gases

JEL Classifications $\mathrm{F} 18 \cdot \mathrm{Q} 50 \cdot \mathrm{Q} 54 \cdot \mathrm{Q} 58$

\section{Introduction}

Regional Emission Trading Systems (ETS) have been popular in the US and Canada, in the EU (the EU ETS covers all 28 member countries plus Norway, Iceland and Liechtenstein) and in China which will switch from a phase of separate emission trading markets in seven pilot regions - which has operated from 2013 to 2017 - to a nationwide system in 2018. The biggest ETS actor in the US is the state of California which has some cooperation with Quebec in Canada - however, the prospects that the US will come on board with a national ETS system of its own in the medium term are almost zero, particularly since the Trump administration has even announced that the US will withdraw from the Paris Agreement. From the perspective of Economics, global ETS could be an ideal method to achieve a reduction of greenhouse gas emissions in an efficient way (for an overview of ETS, both in force and planned, around the world, see Fig. 10 in appendix). The alternative to ETS for internalizing negative external effects could be national Pigou taxes imposed on those activities that generate greenhouse gas (GHG) emissions. In any case, the emission certificate price as well as a Pigou tax are supposed to create incentives for reducing emission-intensive production and for encouraging emission-reducing innovations and the switching from fossil fuels to renewable energies.

For China, the link between these new incentives for reducing GHG emissions and enhancing innovation could be particularly important as China's policy has obviously increasingly emphasized the role of innovation dynamics for future growth and thus appropriate new incentives in the field of climate policy are required.

Regarding a Pigou tax, the general problem is that in the case of cross-border effects one cannot easily impose adequate Pigou tax rates on the relevant source country; the challenge in the case of global warming is that climate protection is a truly global public good. From this perspective, a global ETS could indeed be quite useful provided that the certificate trading price is not subject to very high levels of volatility which, for example, could be caused by broader financial market instabilities. During the Transatlantic Banking Crisis it could be observed that many financial market prices showed a high degree of volatility and this also applied to certificate prices for $\mathrm{CO}_{2}$ trading; this creates the problem that firms and investors, respectively, will find investment decisions with regard to energy-saving technologies to be rather difficult. While it is possible for firms to implement hedging strategies, the optimal investment is rather costly to derive in an environment of high volatility. Countries which are not relying on ETS but are eager to reduce GHG emissions will face higher marginal GHG emission abatement costs than those with certificate trading. Those countries that apply ETS face lower marginal costs in reducing GHG emissions while climate stabilization could generate economic benefits (Stern 2006).

With ETS the speed of adjustment depends partly on competition and hence it is important to maintain a high intensity of competition which helps in the adoption of 
best practice in green technology modernization. Subsequently, we will take a closer look at the EU and China while also raising the question of whether or not ETS in both the EU and China could be sufficient to have a decisive impact on the world economy, i.e. to contribute to the stabilization of the climate.

The share of renewable energy is rising in many countries due to feed-in tariffs and innovation-driven reductions of renewable energy prices over time. It appears to be important that both policymakers as well as investors increasingly focus their attention on compact composite indicators which are compatible with the OECD's requirements for this type of indicator: one example of such a composite indicator is the EIIW-vita Global Sustainability Indicator (Welfens et al. 2016) which includes the share of renewable energy, the "true savings ratio" - according to the World Bank concept and the revealed comparative advantage for environmentally-friendly products so that the strength of the relative green export position (RCA in environmentally-friendly goods; based on the OECD classification) is considered - the latter aspect reflects green innovativeness in the export sector. The EIIW-vita indicator can be downloaded for 140 countries (since 2000) from www.eiiw.eu. China has improved its position in the composite EIIW-vita Global Sustainability Indicator considerably between 2000 and 2015 (+68 rank positions; rank 12 in 2015); with Germany having a lead position in 2015 (see Fig. 1). The ten countries shown in the top section are those that have been the leading ten countries in the field of international competitiveness in environmentally-friendly goods in 2015 - as measured by the sectoral Revealed Comparative Advantage (RCA: if the sectoral export-import ratio is better than the aggregate export-import ratio, there is a positive specialization in environmentallyfriendly products). Leading countries specialized in environmentally-friendly exports are not only Germany and China but also Italy, Japan, Mexico, Austria, Belgium,

\begin{tabular}{|c|c|c|c|c|c|c|}
\hline & \multirow{2}{*}{$\begin{array}{c}\text { GSI Ranking } \\
2000\end{array}$} & \multirow{2}{*}{\multicolumn{3}{|c|}{$\begin{array}{c}\text { GSI Ranking } \\
2015\end{array}$}} & \multicolumn{2}{|c|}{ Difference 2015 vs. 2000} \\
\hline & & & & & Ranking & Total \\
\hline Germany & 21 & 0,1423453 & 1 & 0,29369242 & 20 & 0,151347119 \\
\hline China & 80 & $-0,05342975$ & 12 & 0,19154492 & 68 & 0,244974663 \\
\hline Italy & 57 & 0,03802121 & 23 & 0,10190489 & 34 & 0,063883685 \\
\hline Japan & 2 & 0,22497707 & 64 & 0,00123853 & -62 & $-0,223738545$ \\
\hline Mexico & 70 & $-0,00771644$ & 72 & $-0,02007494$ & -2 & $-0,012358493$ \\
\hline Austria & 22 & 0,14007203 & 15 & 0,16666111 & 7 & 0,026589084 \\
\hline Belgium & 104 & $-0,09939573$ & 87 & $-0,05571457$ & 17 & 0,043681152 \\
\hline Hungary & 131 & $-0,121916$ & 105 & $-0,07987785$ & 26 & 0,042038152 \\
\hline UK & 124 & $-0,11847945$ & 110 & $-0,08929868$ & 14 & 0,029180777 \\
\hline France & 88 & $-0,06846632$ & 85 & $-0,05402329$ & 3 & 0,014443034 \\
\hline & & & & & & \\
\hline \begin{tabular}{|l} 
Luxembourg \\
\end{tabular} & 59 & 0,03670931 & 92 & $-0,06778651$ & -33 & $-0,104495815$ \\
\hline Philippines & 60 & 0,03599443 & 53 & 0,03173631 & 7 & $-0,004258126$ \\
\hline Canada & 45 & 0,0657917 & 41 & 0,07656237 & 4 & 0,010770663 \\
\hline Indonesia & 86 & $-0,06404886$ & 112 & $-0,0950167$ & -26 & $-0,030967838$ \\
\hline Australia & 107 & $-0,10200111$ & 107 & $-0,08616829$ & 0 & 0,01583282 \\
\hline \begin{tabular}{|l|} 
Spain \\
\end{tabular} & 90 & $-0,07429893$ & 66 & $-0,00442707$ & 24 & 0,069871861 \\
\hline Russian Fed. & 94 & $-0,08030676$ & 97 & $-0,06964203$ & -3 & 0,010664727 \\
\hline \begin{tabular}{|l|} 
Singapore \\
\end{tabular} & 100 & $-0,09284587$ & 78 & $-0,03882679$ & 22 & 0,054019087 \\
\hline Ireland & 99 & $-0,09150414$ & 90 & $-0,06517484$ & 9 & 0,0263293 \\
\hline India & 87 & $-0,06813819$ & 108 & $-0,08642566$ & -21 & $-0,018287469$ \\
\hline
\end{tabular}

Fig. 1 Changes in the EIIW-vita Global Sustainability Indicator, 2000 vs. 2015. Source: EIIW database, own calculations 
Hungary, the United Kingdom and France. The bottom ten countries in the field of specialization in environmentally-friendly products were Luxembourg, the Philippines, Canada, Indonesia, Australia, Spain, Russia, Singapore, Ireland and India in 2015. One may argue that Canada, Indonesia, Australia and Russia are major exporters of natural resources and thus have no strong incentive to specialize in environmentally-friendly products (and importing a relatively large share of environmentally-friendly products could help to achieve a strong sustainability position despite the given export specialization - an issue not further explored here).

In terms of the RCA in environmentally-friendly goods, China's improvement is even more remarkable as it shows a changing technological specialization (see Fig. 2). This suggests that China's potential to improve the economic situation in hot spot regions could also be favorable in the long run if adequate framework conditions for the economy are set and appropriate policy measures as well as useful international cooperation (for example, Sino-EU projects) are implemented.

The incentives for investment in countries with a strong positioning in sustainability as measured by the above indicators are, of course, quite important. ETS prices in OECD countries are one element to be considered here, but over time ETS prices have reduced in relative terms (compared to the GDP deflator). There are, however, new perspectives in the EU where the European Commission intends to reduce the allocation of emission permits over time thereby increasing demand and raising prices; at the same time, China's adoption of ETS is a strong push for more global ETS trade. Financial market dynamics could contribute to rather unstable certificate prices under certain conditions.

Figure 3 shows the EU certificate price for carbon allowances in Euro per tonne of $\mathrm{CO}_{2}$ as well as the oil price and the gold price. Basically, one should expect that a rising oil price goes along with a falling demand for oil (and gas) so that the demand for

\begin{tabular}{|c|c|c|c|c|c|c|}
\hline & RCA Ranking & & RCA Ranking & & Difference & 15 vs. 2000 \\
\hline & 2000 & & 2015 & & Ranking & Total \\
\hline Germany & 2 & 0,70732064 & 1 & 0,95120817 & 1 & 0,243887528 \\
\hline China & 129 & $-0,05422317$ & 2 & 0,48314901 & 127 & 0,537372184 \\
\hline Italy & 4 & 0,26478718 & 3 & 0,30370979 & 1 & 0,038922609 \\
\hline Japan & 1 & 0,91144181 & 4 & 0,24871461 & -3 & $-0,6627272$ \\
\hline Mexico & 5 & 0,10790259 & 5 & 0,16448695 & 0 & 0,056584359 \\
\hline Austria & 9 & 0,01363652 & 6 & 0,04517463 & 3 & 0,031538115 \\
\hline \begin{tabular}{|l} 
Belgium \\
\end{tabular} & 10 & 0,01201023 & 7 & 0,04213901 & 3 & 0,030128784 \\
\hline \begin{tabular}{|l} 
Hungary \\
\end{tabular} & 17 & $-0,00608793$ & 8 & 0,03733938 & 9 & 0,043427309 \\
\hline UK & 119 & $-0,02500984$ & 9 & 0,03401491 & 110 & 0,059024746 \\
\hline France & 115 & $-0,01870704$ & 10 & 0,03285886 & 105 & 0,051565896 \\
\hline & & & & & & \\
\hline & & & & & & \\
\hline \begin{tabular}{|l|} 
Luxembourg \\
\end{tabular} & 112 & $-0,01684421$ & 134 & $-0,0238867$ & -22 & $-0,007042487$ \\
\hline \begin{tabular}{|l|} 
Philippines \\
\end{tabular} & 114 & $-0,01832516$ & 135 & \begin{tabular}{|c|}
$-0,02481197$ \\
\end{tabular} & -21 & $-0,00648681$ \\
\hline Canada & 143 & $-0,08429353$ & 136 & $-0,0323785$ & 7 & 0,051915035 \\
\hline Indonesia & 122 & $-0,0286378$ & 137 & \begin{tabular}{|c|}
$-0,03266894$ \\
\end{tabular} & -15 & $-0,004031145$ \\
\hline \begin{tabular}{|l|} 
Australia \\
\end{tabular} & 124 & $-0,0331318$ & 138 & \begin{tabular}{|l|}
$-0,03347561$ \\
\end{tabular} & -14 & $-0,000343816$ \\
\hline Spain & 130 & $-0,0561603$ & 139 & \begin{tabular}{|c|}
$-0,03439802$ \\
\end{tabular} & -9 & 0,021762275 \\
\hline Russian Fed. & 128 & $-0,04572129$ & 140 & \begin{tabular}{|r|}
$-0,04113308$ \\
\end{tabular} & -12 & 0,004588211 \\
\hline Singapore & 131 & $-0,05880113$ & 141 & $-0,0439934$ & -10 & 0,014807731 \\
\hline Ireland & 126 & $-0,03828724$ & 142 & $-0,0442691$ & -16 & $-0,005981856$ \\
\hline India & 120 & $-0,02505041$ & 143 & \begin{tabular}{|l|}
$-0,04879183$ \\
\end{tabular} & -23 & $-0,023741424$ \\
\hline
\end{tabular}

Fig. 2 Changes in the Green RCA Indicator, 2000 vs. 2015. Source: EIIW database, own calculations 
Carbon Allowances, Gold and Crude Oil Prices

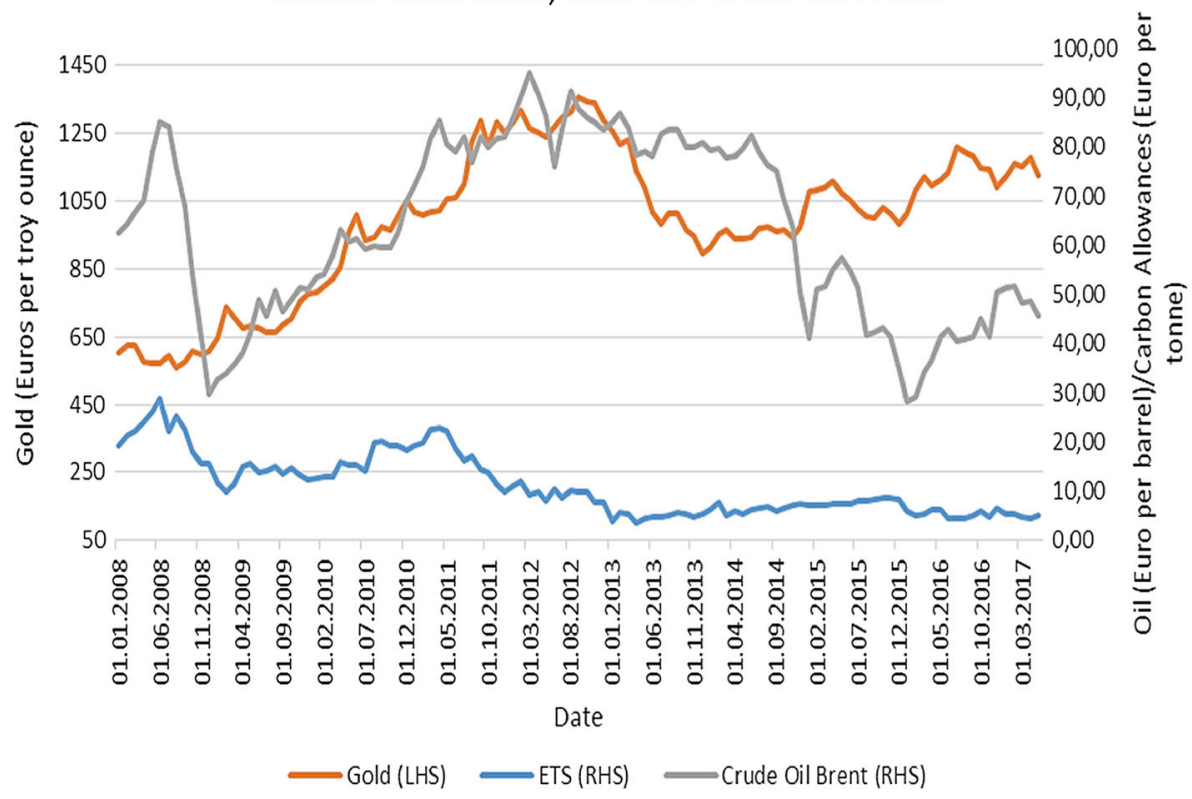

Fig. 3 Prices of Carbon Allowances, Gold and Crude Oil, 2008-2017. Source: Own calculations using data on ETS from Investing.com, data on Gold from the London Bullion Market Association (LBMA) and data on oil from the St. Louis Federal Reserve and the Bank of England

certificates should be positively correlated with the demand for GHG certificates - and here one would have to control for supply-side changes as they occur - if, for example, the European Commission would intervene in the market and buy certificates. The graph is supposed to give a first picture of the relationship between the three prices and no econometric analysis is made here (on the empirical link between gold price and oil price see Beckmann and Czudaj 2013). With regard to the gold price, one may consider this asset price to be part of broader financial market volatility. One may argue in any case that strong financial market volatility could have spillover effects into certificate markets. Financial market activities - if adequately regulated - do not necessarily contribute to instability in the financial sector. On the contrary, the combination of adequate competition policy and banking (de-)regulation could contribute to efficiency gains and positive growth effects as has been discussed in part of the literature.

\section{ETS in China}

The People's Republic of China has actively participated in the global carbon market since 2005 through the Clean Development Mechanism (CDM) under the United Nations Framework Convention on Climate Change (UNFCCC). The CDM was the world's first global carbon market, allowing developing countries who had ratified the Kyoto Protocol to develop and transfer emission reductions from domestic low-carbon projects to industrialized countries who counted these emissions towards their compliance with targets under the Kyoto Protocol. As a result, China now has several years of 
emissions trading experience through the CDM and through the seven pilot carbon markets which were approved by the National Development and Reform Commission (NDRC) in late October 2011 and which started operations in 2013. As can be seen in Fig. 4, the schemes involve two big cities (Beijing and Shanghai), the industrial municipalities of Tianjin and Chongqing, the provinces of Guangdong and Hubei, and the special economic area of Shenzhen. Fujian province became the eighth pilot market in December 2016. In 2017, conditions in China are conducive to the establishment of a national carbon trading market which, once completed, will be the largest carbon emissions trading market in the world. During the first phase, China's carbon market will cover the emission-intensive enterprises in the eight major industrial sectors: petrochemical, chemical, building materials, steel, nonferrous metals, paper, electricity and aviation.

Between 2013 and 2015, the NDRC developed interim administrative ETS measures, as well as sector-specific monitoring and reporting guidelines. Building on this, current work is focused on developing the National ETS Legislation, as well as rules around emissions reporting, verification entities, allocation and offsetting. These regulations are under consultation and are expected to come into force in the first half of 2017. The allowance allocation is also expected to be completed by then.

In 2016, the accumulated trading volume in all the pilot markets accounted for 68.6 MtCO2, with a total value of CNY 1.1 billion (EUR 153 million) (see Figs. 5 and 6). Shenzhen ranked the first for the market value with CNY 298 million, Guangdong saw the largest share of the trading volume $\left(23.4 \mathrm{MtCO}_{2}\right)$. On the other

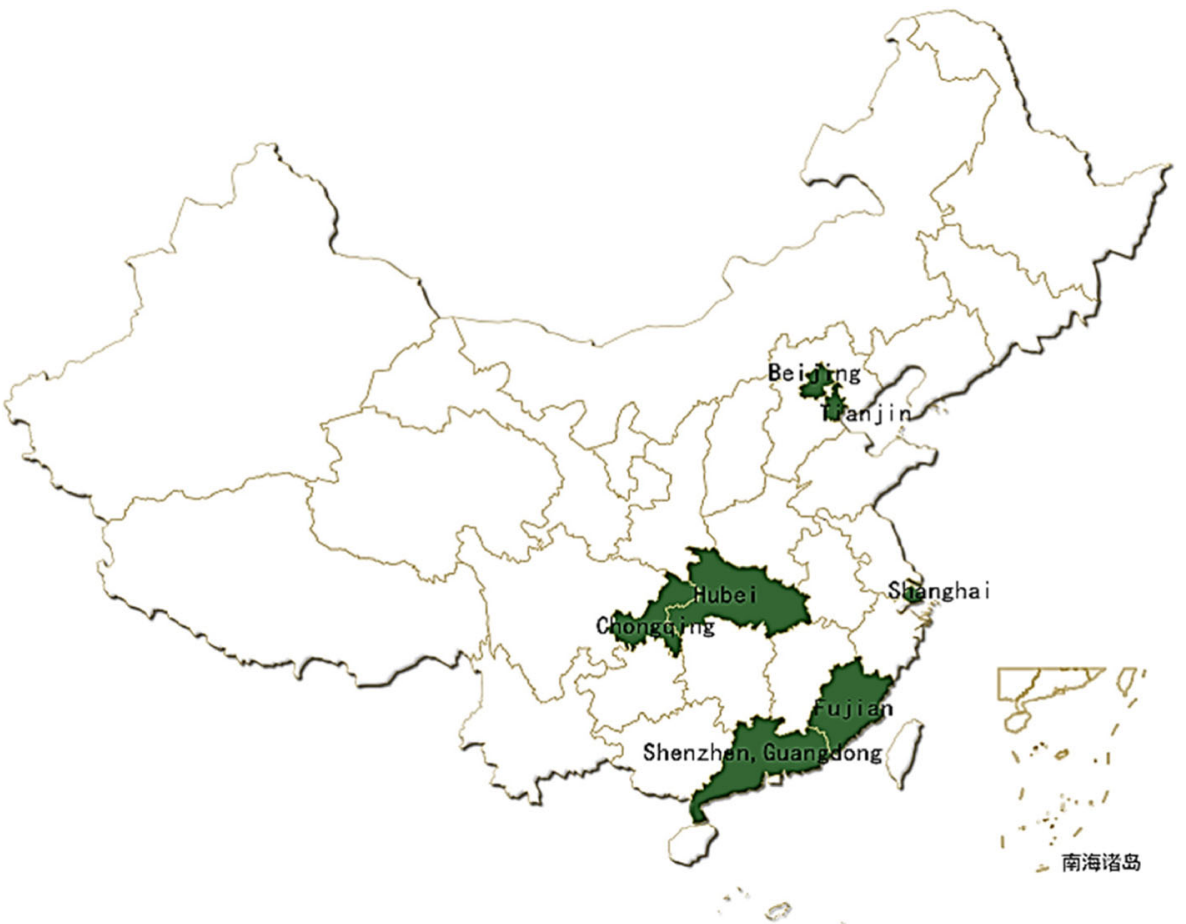

Fig. 4 Locations of the eight pilot ETS markets in China 


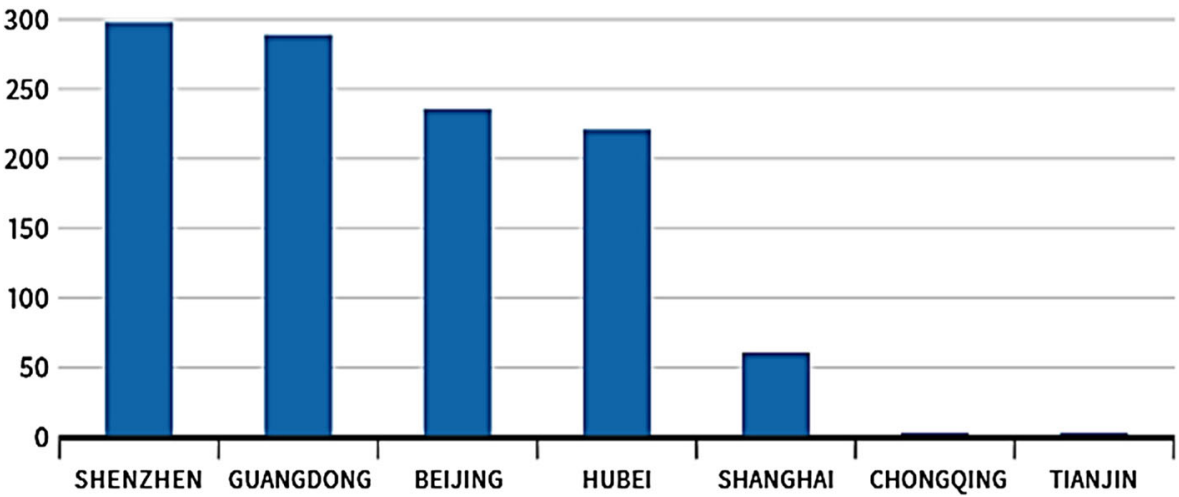

Fig. 5 Accumulated Market Value of China's ETS Pilot Markets in 2016. Source: International Carbon Action Partnership (ICAP) 2017

hand, considering a timeframe from 2014 until now, Hubei ranks the first for both market value (more than CNY 761 million, $32.6 \%$ of total) and market volume (37.69 Mt., $36 \%$ of total).

Figure 7 shows developments in the allowance prices of the EU ETS and the seven Chinese pilot markets from July 2013 to May 2017. In comparing the Chinese pilot markets and the EU ETS, it can be seen that the markets in Beijing and Shenzhen had the closest allowance price to that of the European market.

With the introduction of a nationwide ETS system in China, one can expect that $\mathrm{CO}_{2}$ emissions in China will continue to drop. Assuming that such emissions in China would approach the level of $\mathrm{CO}_{2}$ emissions over a decade or so, an analysis of the $\mathrm{CO}_{2}$ emission figures for the EU in 2013 would indicate that China could potentially reduce emissions by $70 \%$ by 2028 . To illustrate the impact of such a reduction on the global

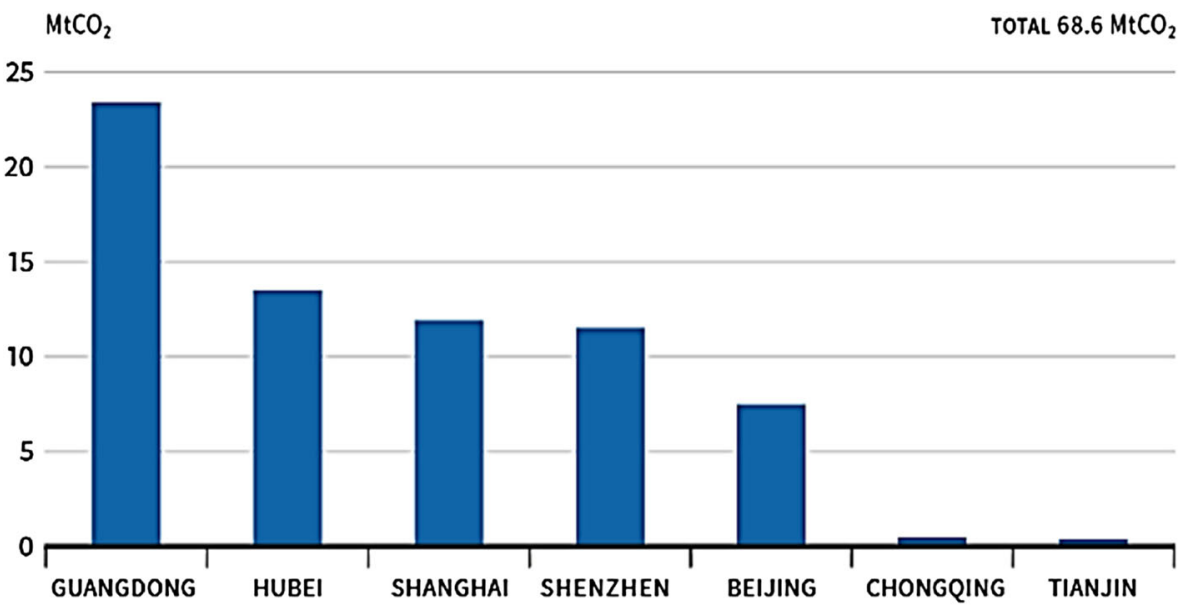

Fig. 6 Accumulated Market Volume of China's ETS Pilot Markets in 2016. Source: International Carbon Action Partnership (ICAP) 2017 


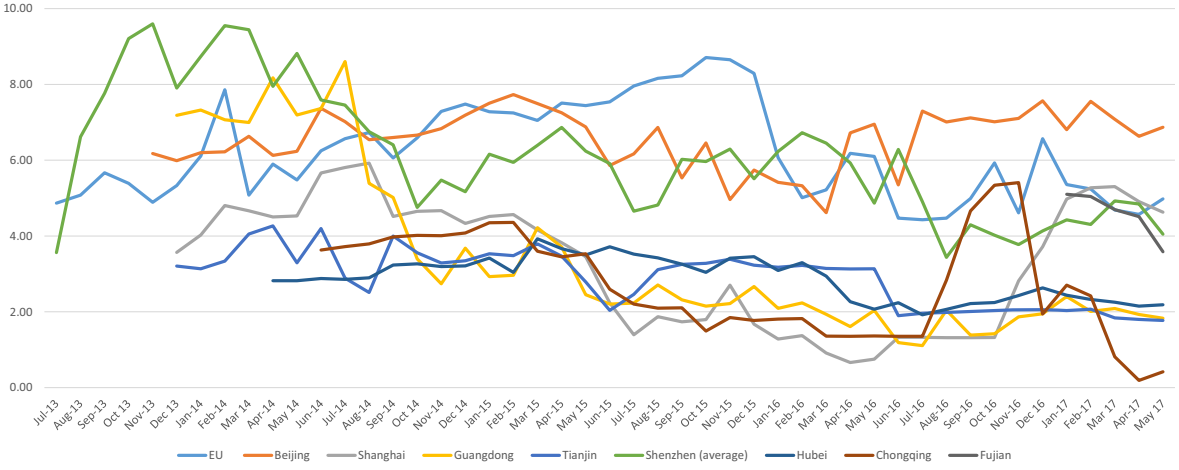

Fig. 7 Carbon Prices from July 2013 to May 2017 (Monthly, Euro/tCO2). Source: Own calculations based on data for China http://www.tanjiaoyi.org.cn/k/index.html and the EU ETS https://www.investing. com/commodities/carbon-emissions-historical-data

scale, it would equate to a global reduction of $\mathrm{CO}_{2}$ in 2013 terms of circa $20 \%$ (see Table 3; Fig. 11 in appendix which are based on data from the World Bank (2017)). However, in Europe the ETS is only one aspect of emission reductions, naturally one must also consider technological progress, other innovations and policy initiatives. Therefore, this hypothesis is intended to be illustrative of the effect that ETS, amongst other developments, could have even if implemented by certain large actors, for example, the EU, China and US.

\section{ETS in the EU}

Climate policy is a key field of action at the European level where international cooperation and a supranational approach, within the framework of the EU, is appropriate. Indeed, the EU has seen more climate policies enacted and implemented than any of other region in the world (Delbeke and Vis 2016). European countries, both collectively and individually, have been at the forefront of international attempts to combat climate change via the United Nations Framework Convention on Climate Change (UNFCCC) and well-known sponsored agreements such as the Kyoto Protocol, the Copenhagen Accord and the Paris Agreement. It is estimated that in 2013, the EU28 was responsible for $7.87 \%$ of global greenhouse gases emissions. This places the EU28 in third place as an emitter of GHG, behind China on $23.67 \%$ and the United States on $12.88 \%$ - including land-use change and forestry (World Resources Institute 2017). According to the WRI data, the European Union has steadily reduced its emissions of GHG since 2006, which led to the EU over-achieving in terms of its GHG reduction target under the first period of the Kyoto Protocol which ran from 2008 to 2012.

The European Union has undertaken a number of EU-level initiatives aimed at countering climate change such as the 2020 climate and energy package, agreed at a 
European Council meeting in 2007 and enacted in legislation in 2009, the 2030 climate and energy framework, and the 2050 low-carbon economy project. These policy initiatives share certain headline targets which should guide the EU towards becoming a "low-carbon economy" by 2050. These targets can be seen in Table 1 .

These targets represent EU-wide goals. In order to achieve these targets in a fair and sustainable way, the burden is shared by the member states according to the Effort Sharing Decision, under which wealthier EU member states (determined based on Gross Domestic Product (GDP) per capita relative to the EU average GDP per capita) should reduce more GHG emissions, while some of the poorer member states, primarily the most recent EU accession states in Eastern European, are allowed to increase emissions - with emissions partly seen as a necessity to facilitate the economic catching up of these countries. The burden of cutting emissions is thus shared to a different extent by different member states, but the burden is also shared by different sectors as can be seen in Fig. 8, with the largest cuts in emissions to come from those sectors covered by the European ETS which covers almost half of the EU's GHG emissions (in particular, the power and industry sectors). It is worth noting that this burden sharing model is also applied with regard to the renewable energy targets, where national targets vary considerably taking each country's relative starting position into account. While the EU is on target to meet its 2020 targets, more efforts should be initiated to meet the targets for 2030 and beyond.

These targets are set and monitored at the EU-level and the EU also enacts legislation designed to facilitate achievement of the targets outlined such as the Renewable Energy Directive and the Energy Efficiency Directive. The EU also supports innovation and funding for Research and Development (R\&D) in renewable energy and other green technologies. However, most of the decisions and actions needed to meet national targets of member state need to be taken and implemented by national policymakers.

The key to the EU achieving its climate policy targets is the EU Emissions Trading System. The ETS was established in 2005 as the world's first carbon trading market, and it remains the global leader as over $75 \%$ of international carbon trading takes place on the ETS (European Commission 2017). The trading market covers all 28 member states of the European Union, along with European Economic Area members Norway,

Table 1 Key Targets of EU Climate Initiatives

\begin{tabular}{llll}
\hline & $\begin{array}{l}2020 \text { climate \& } \\
\text { energy package }\end{array}$ & $\begin{array}{l}2030 \text { climate \& } \\
\text { energy framework }\end{array}$ & $\begin{array}{l}\text { 2050 low-carbon } \\
\text { economy }\end{array}$ \\
\hline Cut GHG Emissions relative to 1990 levels & $20 \%$ & $40 \%$ & $80 \%$ \\
Energy from renewable sources & $20 \%$ & $27 \%$ & \\
Improvements in energy efficiency & $20 \%$ & $27 \%$ & \\
\hline
\end{tabular}

Source: European Commission (2017), Climate Action, Climate Strategies and Targets, available at https://ec. europa.eu/clima/policies/strategies_en 


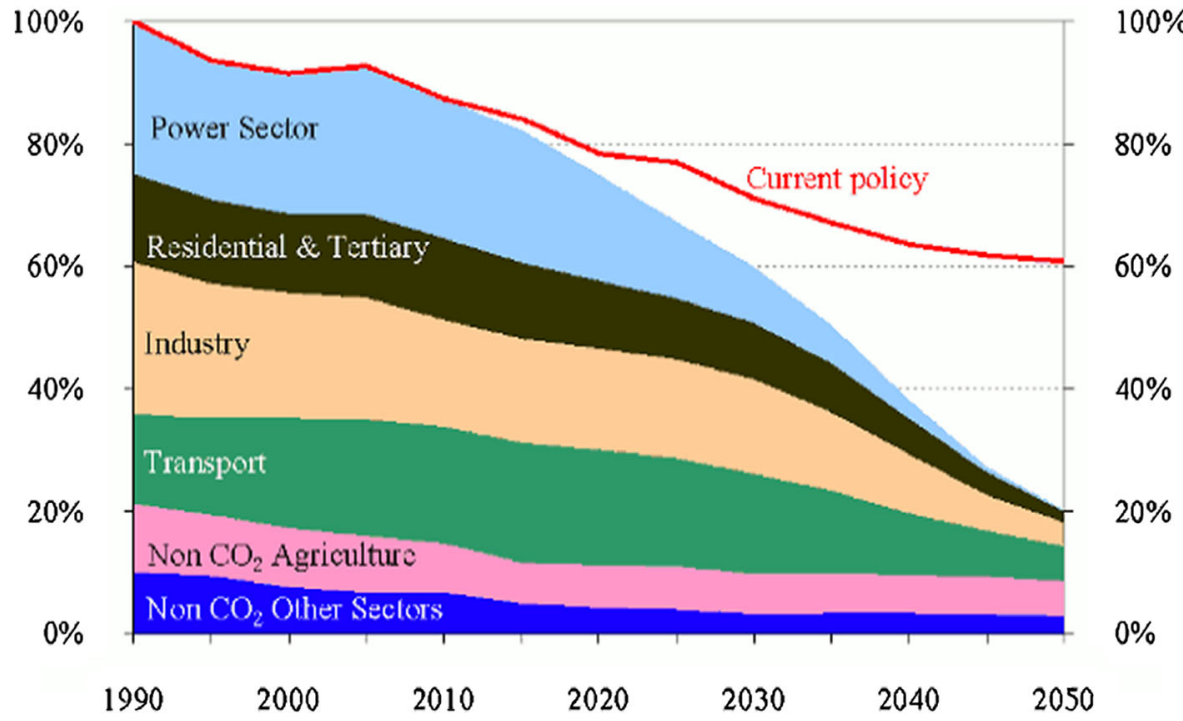

Fig. 8 Possible $80 \%$ Reduction of Greenhouse Gas Emissions in the EU. Source: European Commission, Climate Action, 2050 low-carbon economy, available at https://ec.europa.eu/clima/policies/strategies/2050_en (Greenhouse gas emissions in the EU, 100\% = 1990 levels)

Liechtenstein and Iceland. The ETS operates a 'cap and trade' system, according to which a cap or upper limit can be placed on the total amount of GHG (namely, Carbon Dioxide $\left(\mathrm{CO}_{2}\right)$, Nitrous Oxide $\left(\mathrm{N}_{2} \mathrm{O}\right)$ and Perfluorocarbons (PFCs)) emitted by power plants and manufacturing plants covered under the system. The total number of plants which come under the ETS scheme reaches 11,000 in Europe. This cap can then be reduced easily and cost-effectively over time reducing the supply of allowances and thus increasing the incentive for firms to reduce emissions without the need to purchase allowances. Below the cap, firms can receive free allowances via primary auctions. Firms can buy additional credits or sell unused allowances as required on a secondary market - the ETS. After the year end, firms must be able to submit enough emissions allowances to cover their emissions for the year. Unused allowances can be kept to be used in future years or traded on the market. If the firm is found to have emitted more GHG than they have allowances to cover, heavy fines will be imposed. By establishing a robust price through open trading, the intention is to create and support incentives for firms to invest in renewable energies and low-carbon technologies. Some member states have argued that the surplus of allowances on the market is preventing a robust price from emerging and thus undermining the aforementioned incentives (see Fig. 9).

In April 2016, the European Union signed the Paris Agreement which later entered into force on 4 November 2016. Following President Trump's announcement that the US would withdraw from the Paris Accord, the EU and China jointly agreed to cooperate in terms of GHG reductions, supporting renewable energies and carbon trading.

Subsequently, we briefly look at some individual EU member states and Switzerland (which operates its own emissions trading market). Here, one sees some future developments in relation to the international ETS cooperation and also some of the most important energy-related developments in EU member states, most notably a 


\section{Carbon Allowances (Monthly)}

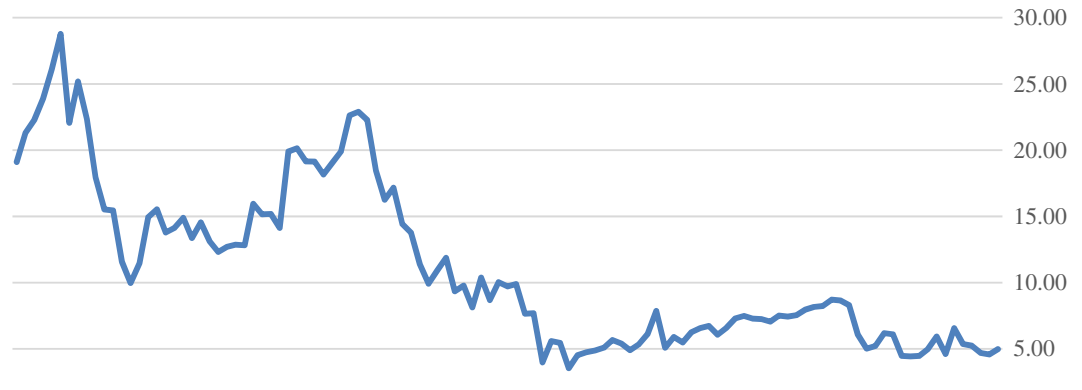

Fig. 9 EU ETS Carbon Allowances Price (€/tonne CO2). Source: Own calculations based on data available at https://www.investing.com/commodities/carbon-emissions

move away from nuclear energy and fossil fuels and towards low-carbon sources of renewable energy.

\subsection{Switzerland}

As an alpine state with a crucial climate-dependent winter tourism sector, Switzerland faces serious challenges in relation to climate change. However, this non-EU member state which is not part of the EU ETS also has significant opportunities to exploit renewable energy sources, particularly hydro-power. The country is currently is a net importer of energy sources, particularly oil which contributes to GHG emissions. The most important piece of environmental legislation in Switzerland is the so-called $\mathrm{CO}_{2}$ Act which has targeted reducing GHG emissions within Switzerland. From 2007, the Swiss Federal Council has focused on four key areas: energy efficiency, renewable energies, the replacement of older power plants and the construction of new plants (including nuclear power plants) and an external energy policy. However, following the Fukushima disaster in 2011, the Federal Council decided to re-examine the Swiss energy policy. The result of this review was Switzerland's plan, titled Energy Strategy 2050. Under this new strategy, the existing nuclear reactors in Switzerland are to be allowed to continue to produce energy until the end of their technically safe operating lives at which point the reactors shall be decommissioned and will not be replaced with new nuclear plants (Federal Office of Energy 2017). Concurrently, a new focus will be on developing renewable sources of energy such as hydroelectric, wind, solar and biomass. The Energy Strategy 2050 was to be implemented in a new Energy Law in 2016, however the matter was put to a referendum on May 21, 2017. In that referendum, the Swiss public voted by $58.2 \%$ to $41.8 \%$ in favor of the proposed gradual phase-out of nuclear power and the support of renewable energy sources (Federal 
Chancellery 2017). The Swiss government has announced intentions to cut GHG emissions by $20 \%$ of 1990 levels by 2020 , and by $50 \%$ of 1990 levels by 2030 . A major element of meeting these targets is Switzerland's own emissions trading market which was introduced in 2008. Following five years of negotiations, it was announced in 2016 that the Swiss ETS will be linked to the EU ETS allowing a certain measure of cooperation (Federal Office of the Environment 2016).

\subsection{United Kingdom}

The United Kingdom operated a voluntary Emissions Trading Scheme between 2002 and 2006 with just 34 participants. This scheme operated as a quasi-pilot for scheme for the EU ETS (DEFRA 2006). In the United Kingdom, the Committee on Climate Change (CCC) was established in accordance with the Climate Change Act of 2008. The CCC is responsible for detailed analysis and advising the government on carbon budgets, emission targets and other measures designed to support energy efficiency and renewable energy sources. The advice of the CCC informs the government's own policies and strategy and is reflected in legislation. Consecutive carbon budgets have set out the UK's emissions cutting targets: 34\% reduction of GHG emissions against 1990 levels by $2020,50 \%$ by 2025 , and $80 \%$ by 2050 (CCC 2017). The long-term 2050 target was made legally binding as early as 2008, making the UK the first country to implement such a binding target in domestic legislation. Other focus areas are building efficiency, electric vehicles. However, BREXIT will have as yet unforeseen consequences for the EU ETS. With circa 1000 of the 11,000 participants in the EU ETS located in the UK (DBEIS 2017), should the UK complete the process of a "hard Brexit" these firms may, or indeed may be obliged, to leave the ETS which may result in challenges for the EU ETS in terms of the burden sharing arrangements, allowances and on the demand-side.

\subsection{Germany}

In Germany, the key word associated with climate policy is Energiewende. Broad legislation on the so-called Energiewende or "energy transition" was passed in 2010, before the Fukushima disaster. Under this policy, Germany should transition to being a low-carbon economy with a reliable and sustainable energy supply from renewable sources. Initially, nuclear power was seen as an alternative to fossil fuels and coalpowered plants, however following the Fukushima disaster in 2011, a crucial aspect of the transition was added - the phasing-out of Germany's nuclear reactors. Germany targets a $40 \%$ cut in GHG emissions by 2020, and 80-95\% cut in emissions by 2050 . Significant cuts in primary energy consumption and the share of renewable energy are also part of Germany's plan to meet its energy and climate policy goals. However, trading carbon emission allowances is likely to be strong in Germany as Europe's largest economy.

\subsection{Sweden}

In Sweden, a Cross-Party Committee on Environmental Objectives reporting in 2016 has proposed a climate policy framework possibly the most drastic targets of any 
country with regard to emission cuts. Under this new framework proposal, Sweden will adopt a long-term climate goal which means that by 2045 Sweden will have no net emissions of greenhouse gases. To meet this target would entail an $85 \%$ reduction of GHG emissions in relation to 1990 levels. The remaining emissions will be offset by Swedish investment in and support of projects abroad. From 2045 on, it is envisaged that Sweden will attain a situation of negative net emissions by keeping domestic emissions down and increasing support abroad. To help achieve this long-term goal, the government of Sweden has set-out an emission pathway with intermediate targets, government planning and follow-up measures, frequent reports on progress to the Swedish parliament (including annual reports) and the establishment of a climate policy council which would examine the implemented policy on an ongoing basis and assess whether it is compatible with the national climate objectives (Government of Sweden 2016). The proposals also support actions at an EU-level to strengthen the EU ETS system, as the low price for carbon is seen as not representing a sufficient inducement to encourage firms to limit emissions. As a result of its ambitious targets and efforts to reinforce EU measures, Sweden topped Carbon Market Watch's EU Climate Leader Board, ahead of Germany and France, with 67 points from a possible 100 indicating full compatibility with the Paris Agreement (Carbon Market Watch 2017). In January 2017, it was announced by the Swedish Prime Minister that Sweden would enact the climate change law with effect from 1 January 2018 (Darby 2017).

\subsection{France}

France's low-carbon strategy stems from the Energy Transition for Green Growth Act 2015 which was enacted prior to the COP21 in Paris. This national strategy seeks to help France achieve the targets set for cutting emissions which have been agreed at an EU-level. Thus France aims at a 40\% reduction (relative to 1990 levels) in GHG emissions by 2030 , and has set a target of reducing emissions by $75 \%$ by 2050 (French Ministry of the Environment, Sustainable Development, and Energy 2015). Similar to Germany and Switzerland, France is also moving away from nuclear energy but cannot completely end nuclear power production due to its large share. Under the clean energy law passed in 2015, France will cut the share of the power mix produced by nuclear power plants from around $75 \%$ in 2015 to $50 \%$ by 2025 . With a targeted cut in energy consumption, renewable energy sources should account for over $30 \%$ of the power mix in the future. Furthermore, a pigovian carbon tax on emission producing fuels such as gas and coal not already covered under the EU ETS, will be increased over time from $€ 14.50$ per tonne in 2015 , to $€ 56$ in 2022 increasing up to $€ 100$ per tonne by 2030 (French government 2015).

\section{Policy perspectives}

Switching to ETS in China will generate considerable benefits for Asia and the world economy. Emission-intensive production will be relocated from China to Asian partner countries and a higher green innovation intensity in China will help to reduce GHG emissions. The Asian Infrastructure Investment Bank provides opportunities for China to encourage the introduction of ETS in neighboring countries. This in the end could bring a 
double economic and political dividend for China whose reputation gains in the global green community. The benefits from regional infrastructure projects could be rather large.

If the US does not adopt a nationwide ETS while China and the EU have implemented emission certificate trading, then the pressure on the US will become stronger over time. This could be the first time that the US is facing pressure to follow the EU and China which would be counter to the traditional G20 leadership. The reduction of economic growth in China in the context of a national ETS system is likely to be minimal if one considers the strong improvement of China's revealed comparative advantage in environmental-friendly goods over time as calculated in the form of the EIIW-vita global sustainability indicator (Welfens et al. 2016).

Part of GHG emissions is related to consumption, part is due to the use of machinery for producing goods. Thus the capital intensity $\mathrm{k}:=\mathrm{K} / \mathrm{L}$ ( $\mathrm{K}$ is the capital stock, $\mathrm{L}$ is labor) plays a role for emissions. In an enhanced neoclassical growth model it is obvious that the steady state capital intensity $\mathrm{k \#} \mathrm{( \#} \mathrm{is} \mathrm{steady} \mathrm{state)} \mathrm{could} \mathrm{be} \mathrm{above}$ the "golden rule $\mathrm{k}$ " which maximizes per capita consumption $\mathrm{C} / \mathrm{L}$ ( $\mathrm{C}$ is consumption). If market dynamics bring about a ratio $\mathrm{K} / \mathrm{L}$ that is above this level the $\mathrm{CO}_{2}$ emissions could be reduced while per capita consumption can be raised (Welfens 2017a). This means that governments should be careful to take into account basic insights from growth models and take the golden rule as a useful policy concept.

It may also be emphasized that broad recycling policy initiatives could be quite useful for both OECD countries and the BRICS: the benefits can be well understood in an enhanced ecological Solow growth model (Welfens 2017b) in which part of labor is used for recycling activities R" (parameter $\varphi$ ) which in turn effectively reduce the depreciation rate of capital $\delta$ (this is the normal depreciation rate). The new depreciation rate is $\delta "=\left(1-R^{\prime \prime}\right) \delta$. With a savings function $\mathrm{S}=$ $\left(\mathrm{s}(1-\tau)+\mathrm{s}^{\prime} \tau \tau^{\prime}\right) \mathrm{Y}\left(0<\mathrm{s}<1, \mathrm{~s}^{\prime}>0, \tau\right.$ is the income tax rate, $\tau$ is the VAT rate $)$ and a rather simple macro production function $Y=(M / P)^{\beta} K^{\beta}\left(A L\left(1-\varphi R^{\prime c}\right)\right)^{1-\beta-\beta,}$, one gets a steady state solution for the capital intensity $k^{\prime} \#\left(k^{\prime}:=K /(A L) ; M\right.$ is the stock of money, $\mathrm{m}^{\prime}:=(\mathrm{M} / \mathrm{P}) /(\mathrm{AL}), \mathrm{P}$ the price level; $0<\beta<1 ; 0<\beta^{\prime}<1$; knowledge $\mathrm{A}$ and labor input $\mathrm{L}$ are assumed to grow at rate a and $n$, respectively: $\mathrm{k}^{\prime} \#=[(\mathrm{s}(1-\tau)+$ $\left.\left.s^{\prime} \tau^{\prime} \tau\right) m^{, \beta^{\prime}}\left(1-\varphi R^{\prime \prime}\right)^{1-\beta-\beta^{\prime}} /\left(\left(1-R^{\prime \prime}\right) \delta+a+n\right)\right]^{1 /(1-\beta)}$. It is easy to see that the input requirements for recycling - see the term $\varphi \mathrm{R}$ “- reduces the level of the growth path in the steady state while the improvement effect in the capital depreciation rate (see the term $\left(1-\mathrm{R}^{\prime \prime}\right) \delta$ ) is raising the level of the growth path. Therefore one can also raise the question of what is the long-run output per capita maximizing recycling intensity - or what is the optimum R". It is obvious that improved recycling is one pillar of a circular national and global economy.

In an open economy there could be international transfer of recycling knowledge which raises the issue of cooperation in recycling innovations of the US, the EU, China and Japan. While this is mainly a question for industrial firms and government policies, respectively, the issue of encouraging households to become more active in recycling and to purchase recycled goods more often is probably more related to education, adequate labeling and green social digital networks.

A key policy issue also concerns the strategic orientation of investment funds and investors, respectively. One could emphasize here the problem of decarbonization and therefore the risk related to investing in natural resources and products that are GHG intensive in the production process. Many investors 
already have these challenges on their portfolio radar. An equally interesting aspect is whether or not international investors are developing some preference for countries that are leading in the field of sustainability - for example, those with a leading position in the EIIW-vita Global Sustainability Indicator. There is still research needed in order to understand whether there is a positive link between, for example, the EIIW-vita global sustainability ranking and the longrun stock market performance of the respective countries. However, there are some solid arguments indeed why one may expect countries with an ambitious environmental regulation to stimulate innovations in general and those in environmentally-friendly products in particular. This should lead to a higher output growth and, with per capita income rising, the demand for a clean environment should intensify in households. Thus the quality of life is improved in this pro-sustainability setting which in turn facilitates attracting the best scientists, managers, skilled workers or students from countries all over the world (with Switzerland or California - as a US state - apparently being good examples here). In this respect, it is interesting that China has become one of the leading countries where students from Europe like to study abroad and with air quality further improving in the future - for example, in the context of growing electro-mobility - China's position could improve even more over time. With sustained output growth, ecological modernization will remain a policy priority in China. What is lacking to some extent is a stronger cooperation between the EU (Eurozone), China, Japan and the US; ranging from macroeconomic policy to green innovation policy. These four countries stand for a group of independent actors: the policy action of each country has a domestic impact as well as an impact on the other three big economies and there will be repercussion effects to be considered from these big partners. An isolated policy strategy thus is doubtful and a cooperation forum such as the G20 could be quite useful as an institutional basis for enhanced cooperation.

China's implementation of ETS will be a big step forward for China and the world economy. ETS trade should become global in the long run. From this perspective the role of G20 countries in ETS should be reinforced (see Table 2 on GDP and $\mathrm{CO}_{2} / \mathrm{GHG}$ shares of G20 countries). Here the future long run income convergence may be expected to facilitate consensus building in this rather heterogeneous group. International cooperation in R\&D policy of the EU and China as well as other countries could be quite useful in the long run. EU countries and China might want to consider options for stronger multilateral cooperation in the future - as the Trump administration has emphasized America First, undermining multilateralism (and hence the role of International Organizations) and bilateralism. With the US retreating from global leadership new Sino-EU political cooperation is inconceivable.

The European ETS is working, but it suffers from the rather low price of emission allowances. The long-term time horizon 2050 in the EU climate policy is rather ambitious and it is unclear whether or not a consistent G20 approach can be achieved - with the EU, China, Japan and the US cooperating amongst each other. There is a lack of specialized climate stabilization institution in the world economy, the traditional anchoring of climate policy in the UN weakens the practical pressure for efficient cooperation since the $\mathrm{UN}$ is very heterogeneous in terms of per capita income and GHG emissions per unit of GDP; G20 might be an institution that is suitable for effective policy cooperation. 
Acknowledgements This paper draws on research performed within the research project "SINCERE". The financial contribution of the DFG, the German Research Foundation, is acknowledged. This study is also financially supported by the Natural Science Foundation of China (71325006, 71690241, 71461137008), the Fundamental Research Funds for the Central Universities through Shanghai Jiao Tong University (16JCCS04), the Shanghai Municipal Government (17XD1401800). Funding for Open Access from EIIW/ vita Foundation is gratefully acknowledged.

\section{Appendix}

Table 2 G20 countries ranked in order of 2013 greenhouse gas (GHG) emissions (as percentage of total G20 GHG emissions) including land-use change and forestry

\begin{tabular}{|c|c|c|c|c|c|}
\hline & $\begin{array}{l}\mathrm{CO} 2 \text { share } \\
\text { in } 2008\end{array}$ & $\begin{array}{l}\text { CO2 share } \\
\text { in } 2013\end{array}$ & $\begin{array}{l}\text { GDP PPP share } \\
\text { in } 2008\end{array}$ & $\begin{array}{l}\text { GDP PPP share } \\
2013\end{array}$ & $\begin{array}{l}\text { GHG share } \\
\text { in } 2013\end{array}$ \\
\hline China & $26 \%$ & $34 \%$ & $13 \%$ & $18 \%$ & $30 \%$ \\
\hline US & $20 \%$ & $17 \%$ & $19 \%$ & $18 \%$ & $16 \%$ \\
\hline EU & $14 \%$ & $11 \%$ & $22 \%$ & $20 \%$ & $10 \%$ \\
\hline India & $6 \%$ & $7 \%$ & $6 \%$ & $7 \%$ & $8 \%$ \\
\hline Indonesia & $2 \%$ & $2 \%$ & $2 \%$ & $3 \%$ & $6 \%$ \\
\hline Russia & $6 \%$ & $6 \%$ & $4 \%$ & $4 \%$ & $5 \%$ \\
\hline Japan & $4 \%$ & $4 \%$ & $6 \%$ & $5 \%$ & $4 \%$ \\
\hline Brazil & $1 \%$ & $2 \%$ & $3 \%$ & $3 \%$ & $3 \%$ \\
\hline Canada & $2 \%$ & $2 \%$ & $2 \%$ & $2 \%$ & $2 \%$ \\
\hline Germany & $3 \%$ & $3 \%$ & $4 \%$ & $4 \%$ & $2 \%$ \\
\hline Mexico & $2 \%$ & $2 \%$ & $2 \%$ & $2 \%$ & $2 \%$ \\
\hline Rep. of Korea & $2 \%$ & $2 \%$ & $2 \%$ & $2 \%$ & $2 \%$ \\
\hline Saudi Arabia & $2 \%$ & $2 \%$ & $1 \%$ & $2 \%$ & $1 \%$ \\
\hline United Kingdom & $2 \%$ & $2 \%$ & $3 \%$ & $3 \%$ & $1 \%$ \\
\hline Australia & $1 \%$ & $1 \%$ & $1 \%$ & $1 \%$ & $1 \%$ \\
\hline South Africa & $2 \%$ & $2 \%$ & $1 \%$ & $1 \%$ & $1 \%$ \\
\hline Argentina & $1 \%$ & $1 \%$ & $1 \%$ & $1 \%$ & $1 \%$ \\
\hline Italy & $2 \%$ & $1 \%$ & $3 \%$ & $2 \%$ & $1 \%$ \\
\hline France & $1 \%$ & $1 \%$ & $3 \%$ & $3 \%$ & $1 \%$ \\
\hline Turkey & $1 \%$ & $1 \%$ & $1 \%$ & $2 \%$ & $1 \%$ \\
\hline G20 & $100 \%$ & $100 \%$ & $100 \%$ & $100 \%$ & $100 \%$ \\
\hline
\end{tabular}

G20 in the world economy - G20 share of global GDP (based on PPP): $80 \%$, G20 share of global GHG Emissions: $79 \%$. GHG share relates to Total GHG Emissions Including Land-Use Change and Forestry $\left(\mathrm{MtCO}_{2} \mathrm{e}\right)$

Source: Own calculations using the World Bank Word Development Indicators and the World Resource Institute (2017). Available online at: http://cait.wri.org 
Table 3 Potential extent of future $\mathrm{CO} 2$ emissions reductions for China and the World

\begin{tabular}{lllll}
\hline & $\begin{array}{l}\text { CO2 Emissions } \\
\text { (kg per PPP \$ GDP) }\end{array}$ & China GDP PPP (million) & $\begin{array}{l}\text { Emissions kg per PPP \$ GDP } \\
\text { *GDP }\end{array}$ & \\
\hline EU & 0,195 & $18,610,463,98$ & $3,629,040,48$ & \\
China & 0,632 & $18,610,463,98$ & $11,761,813,24$ & Absolute \\
Difference & & $-8,132,772,76$ & $\%$ \\
Difference (\%) & & $-69,15$ & kt CO2 \\
Actual emissions & & & $10,249,463,00$ & $\mathrm{kt}$ CO2 \\
China & & $7,224,846$ & $\mathrm{kt}$ CO2 \\
Reduction & & $35,848,592$ & $\%$ \\
World CO2 emis & & 20,15 & \\
Reduction & & & & \\
\hline
\end{tabular}

All GDP figures in 2011 Constant International Dollars

Source: Own calculations using data from World Bank, World Development Indicators

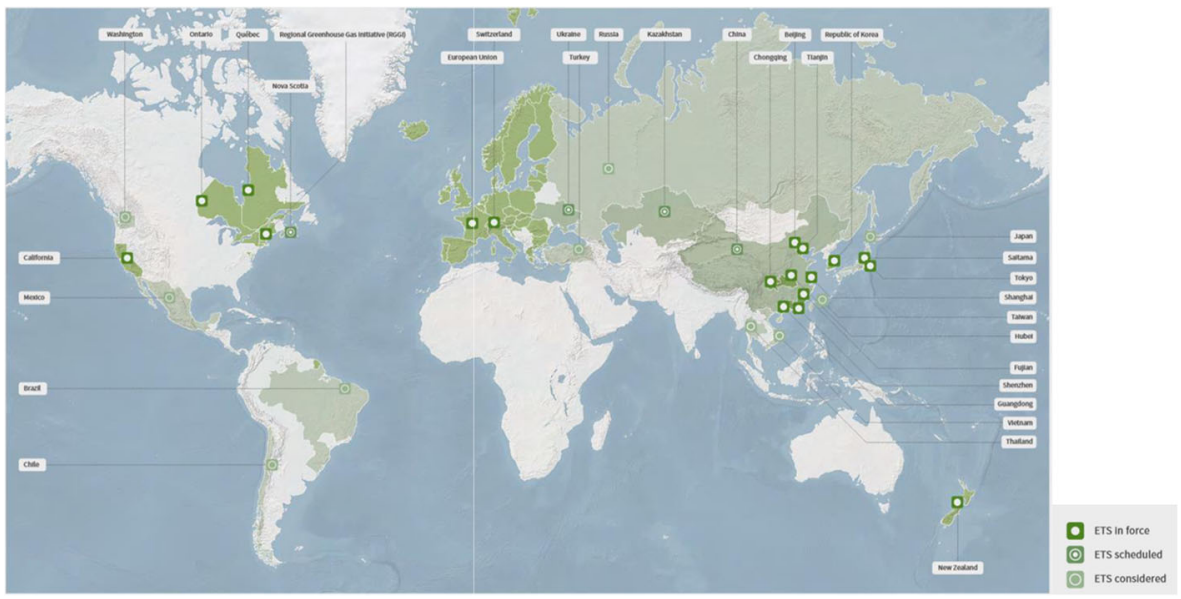

Fig. 10 ETS in force, scheduled and considered around the world. Source: International Carbon Action Partnership (ICAP) 2017 
CO2 emissions (kg per PPP \$ of GDP)

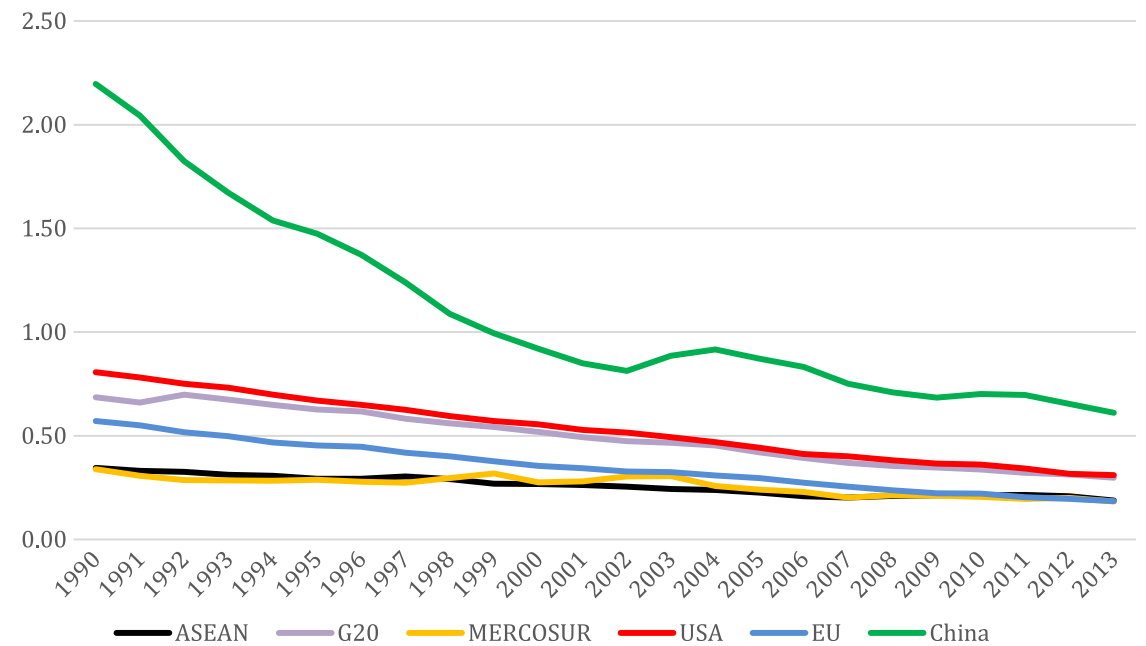

Fig. 11 CO2 Emissions. Source: World Bank (2017), World Development Indicators

Open Access This article is distributed under the terms of the Creative Commons Attribution 4.0 International License (http://creativecommons.org/licenses/by/4.0/), which permits unrestricted use, distribution, and reproduction in any medium, provided you give appropriate credit to the original author(s) and the source, provide a link to the Creative Commons license, and indicate if changes were made.

\section{References}

Beckmann J, Czudaj R (2013) Oil and gold price dynamics in a multivariate cointegration framework. IEEP 10:453-468

Carbon Market Watch (2017) EU climate leader board, where countries stand on the Effort sharing regulation - Europe's largest climate tool, policy briefing, March 2017. http://carbonmarketwatch.org/wpcontent/uploads/2017/03/EU-Climate-Leader-Board-Where-countries-stand-on-the-Effort-SharingRegulation-\%E2\%80\%93-Europe\%E2\%80\%99s-largest-climate-tool_final.pdf

Committee on Climate Change (2017) Carbon budgets: how we monitor emissions targets https://www.thecce. org.uk/tackling-climate-change/reducing-carbon-emissions/carbon-budgets-and-targets/

Darby M (2017) Sweden set to bring in climate law by 2018. http://www.climatechangenews.com/2017/02/02 /sweden-set-to-bring-in-climate-law-by-2018/

Delbeke J, Vis P (2016) EU climate policy explained. In: Delbeke J and Vis P (eds) EU climate policy explained. https://ec.europa.eu/clima/sites/clima/files/eu_climate_policy_explained_en.pdf

Department for Environment, Food and Rural Affairs (2006) Appraisal of years 1-4 of the UK emissions trading scheme. Report by Enviros Consulting Ltd December 2006

Department of Business, Energy and Industrial Strategy (2017) Participating in the EU ETS. https://www.gov. uk/guidance/participating-in-the-eu-ets\#history

European Commission (2017) Climate Action, The EU Emissions Trading System (EU ETS). https://ec. europa.eu/clima/policies/ets en

Federal Chancellery (2017) Vorläufige amtliche Endergebnisse, Energiegesetz (EnG) vom 30.09.2016. https://www.admin.ch/ch/d/pore/va/20170521/det612.html

Federal Office of Energy (2017) What is the Energy Strategy 2050? http://www.bfe.admin. ch/energiestrategie2050/06445/index.html?lang=en 
Federal Office of the Environment (2016) Linking the Swiss and EU emissions trading schemes. https://www. bafu.admin.ch/bafu/en/home/topics/climate/info-specialists/climate-policy/emissions-trading/linking-theswiss-and-eu-emissions-trading-schemes.html

French Government (2015) Energy transition. http://www.gouvernement.fr/en/energy-transition

French Ministry of the Environment, Sustainable Development, and Energy (2015) National Low Carbon Strategy. http://unfccc.int/files/focus/long-term_strategies/application/pdf/national_low_carbon_strategy_ en.pdf

Government of Sweden (2016) A climate policy framework and a climate and clean airstrategy for Sweden. http:/www.government.se/articles/2016/07/a-climate-policyframework-and-a-climate-and-clean-airstrategy-for-sweden/

International Carbon Action Partnership (ICAP) (2017) Emissions Trading Worldwide, International Carbon Action Partnership (ICAP) Status Report 2017

Stern N (2006) Stern Review on the Economics of Climate Change, commissioned by the Government of the United Kingdom

Welfens PJJ (2017a) Macro Innovation Dynamics and the Golden Age, Heidelberg: Springer

Welfens PJJ (2017b) Recycling in an Enhanced Solow Model of Sustainable Growth. European Institute for International Economic Relations (EIIW) Working Paper No. 241

Welfens PJJ, Perret J, Irawan T, Yushkova E (2016) Towards Global Sustainability: Issues, New Indicators and Economic Policy, Heidelberg: Springer

World Bank (2017) World Development Indicators. http://data.worldbank.org/datacatalog/worlddevelopment-indicators

World Resources Institute (2017) CAIT Climate Data Explorer. http://cait.wri.org 